\title{
Self-perceived readiness of medical interns in performing basic medical procedures at the Universitas Academic Health Complex in Bloemfontein
}

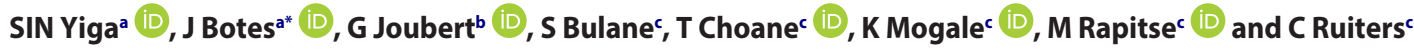 \\ ${ }^{a}$ Faculty of Health Sciences, Department of Family Medicine, University of the Free State, Bloemfontein, South Africa \\ ${ }^{b}$ Faculty of Health Sciences, Department of Biostatistics, University of the Free State, Bloemfontein, South Africa \\ 'Faculty of Health Sciences, School of Medicine, University of the Free State, Bloemfontein, South Africa \\ *Corresponding author, email: botesj@ufs.ac.za
}

Background: Medical internship in South Africa is a two-year period after completing the basic medical degree. Interns rotate through six different domains, where they are exposed to various clinical procedures. These skills are often not up to standard, and interns feel unprepared for future challenges.

This study evaluated the self-perceived readiness of interns rotating through the Universitas Academic Health Complex in performing basic medical procedures, and the frequency of performing these procedures.

Methods: This was a descriptive quantitative study. Consenting participants completed an anonymous questionnaire regarding four pre-selected medical procedures per department.

Results: The majority of the 61 participants were second-year interns (52.5\%), female (54.0\%), with a median age of 25 years. Interns felt ready to perform the majority of procedures, but more than $50 \%$ reported not being ready to perform circumcisions, episiotomy and perineal repair, assisted delivery and appendectomies. Some procedures in Family Medicine, Internal Medicine, Obstetrics and Gynaecology, General Surgery and Psychiatry were rarely performed by at least half of the participants.

Conclusions: Exposure of medical students during their clinical years to practical training is inadequate. The focus in the MBChB curriculum should be increased to a more specific practical approach during both the pre-clinical and clinical years.

Keywords: basic medical procedures, education, medical interns, readiness, skills

\section{Introduction}

It is common practice to have an apprenticeship (otherwise known as medical internship) period after medical students complete their basic medical degree. ${ }^{1}$ This is considered a 'bridging' period for newly qualified doctors between acquired knowledge and required skills. ${ }^{2}$ In South Africa, qualified doctors registered with the Health Professions Council of South Africa (HPCSA) are now required to complete a two-year supervised medical internship period at an accredited hospital. Interns are exposed to various aspects of basic clinical procedures, which are achieved by rotating through the required medical domains. ${ }^{3,4}$ These domains, consisting of eight departments, include Internal Medicine, General Surgery, Paediatrics, Obstetrics and Gynaecology, Anaesthesiology and Orthopaedics, and Family Medicine and Psychiatry. ${ }^{1,4}$
\end{abstract}

Internship provides newly qualified doctors with the opportunity to gain competence and experience in teamwork, attitude, values and basic clinical skills. ${ }^{3}$ In a study at the University of Cape Town, the importance of testing students' perception of their own competence in procedural skills was highlighted. ${ }^{5}$ Low self-belief in a specific area may indicate a gap in the curriculum, or require training enhancements.

High-pressure challenges in environments different from their initial training are priceless in educational value for medical interns who are now faced with the realities of being a doctor. They are able to gain insight into the patient population they will serve through exposure that lectures, books and laboratory simulations simply cannot provide. A study in Ireland compared final-year students'and interns' perception of their undergraduate skills training, and found that the interns were much less satisfied with their training and skill needs after experiencing actual situations during their rotations. ${ }^{6}$ Thus, when analysing perceived competence, the ideal time to conduct the review would be during the internship when the junior doctor's knowledge and skills have been put to the test.

Medical schools have the responsibility to prepare students for their internship. ${ }^{7}$ These academic institutions should lay the foundation for essential procedural skills, which graduates require when they face internship and their future careers., Unfortunately, such a list of skills is not easily defined, as the required skills differ from country to country, province to province, district to district, and even between rural and urban areas. Specialist disciplines may also differ in their opinion on the basic skills from that of primary care physicians. Considering the uneven share of the global disease burden that we are experiencing in sub-Saharan Africa, the complexity of preparing a medical curriculum encompassing all required skills is obvious. Even with this responsibility towards the local area stakeholders, medical schools are now pressured to deliver internationally standardised, but highly qualified doctors who can make a seamless transition when moving abroad., ${ }^{3,9}$

The transition from medical students to junior doctors is an exciting, but often a daunting challenge for final-year medical students and new medical interns. Even after adapting and improving the undergraduate curriculums and rotation policies for internship, gaps in the procedural skills are still evident. ${ }^{7}$ A call for a standardised core undergraduate curriculum in procedural skills was made by Jaschinski and De Villiers after their study at a Western Cape hospital indicated gaps in medical interns' abilities. ${ }^{8}$ The interns improved on their skillset and confidence 
during their rotations, but the researchers felt the internship should be a period where skills and knowledge should be built on, rather than learning what should have been taught before graduation.

\begin{abstract}
Aim
This study aimed to determine the self-perceived readiness of medical interns at the Universitas Academic Health Complex to perform basic medical procedures, and the frequency of performing these procedures.
\end{abstract}

\section{Methods}

This was a descriptive quantitative study conducted from October 2011 to January 2012 on all medical interns rotating at Universitas Academic Health Complex in Bloemfontein. The Universitas Academic Health Complex consists of Universitas Academic Hospital, Pelonomi Tertiary Hospital, National District Hospital and the Free State Psychiatric Complex. All four hospitals are accredited for internship training. Medical interns rotate through all these hospitals depending on the location of the medical domains required for certification.

Medical interns eligible for inclusion in the study were all first-, second- or extension-year interns who rotated in the Departments of Anaesthesiology, Family Medicine, Psychiatry, Internal Medicine, Obstetrics and Gynaecology, General Surgery, Orthopaedics and Paediatrics of the four hospitals, at the time of the study. The seven pilot-study participants (rotating in the Department of Family Medicine) were excluded, as was one intern who did not consent to participate. After the pilot study, adjustments were made to the questionnaire where problems were identified.

For the main study, the revised anonymous self-evaluation questionnaire was utilised as the measuring instrument to quantify the medical interns' opinions regarding their readiness in performing basic medical procedures. During the weekly departmental meetings the questionnaires, available in English and Afrikaans, were distributed and completed by the consenting participants. General information such as gender, age, length of degree, and year and place of internship was collected. Participants had to indicate the departments they had worked in during their internship, medical procedures they had performed as undergraduates and how they had received their practical undergraduate training. The main procedures listed under each domain in the Internship Guidelines ${ }^{1}$ were selected and added as questions to determine pre-qualification exposure.

Self-perceived readiness to perform basic medical procedures and the frequency at which these pre-selected medical procedures were performed were rated using the following two scales: readiness consisted of $1=$ 'not ready at all', $2=$ 'not so ready', 3 ='ready' and $4=$ 'very ready', while frequency consisted of $1=$ 'never', 2 = 'rarely' and $3=$ 'frequently'. For reporting of results readiness scores 1 and 2 were grouped together, and 3 and 4 were grouped together. Frequency scores 1 and 2 were grouped together. Only interns who had already rotated through a specific department were requested to answer the questions on procedures related to that department.

Data were analysed by the Department of Biostatistics, Faculty of Health Sciences of the University of the Free State. The study protocol was approved by the Ethics Committee of the Faculty of Health Sciences, University of the Free State. The Provincial Curator and the Heads of the hospitals gave permission to conduct the study. In order to maintain anonymity no identifying information was captured on the questionnaires.

\section{Results}

Of the 62 possible participants, 61 completed the questionnaires. Socio-demographic information is given in Table 1. The participants were mostly female (54.1\%) and in their second year of internship (52.5\%). None of the participants were in their extension year. The median age of the participants was 25 years (range 23 to 33 years). More than half (52.5\%) of the participants completed their $\mathrm{MBChB}$ degree at the University of the Free State.

Most participants received their practical training by performing procedures themselves (95.1\%), followed by first-hand observation (88.5\%). The majority of participants (78.2\%) indicated that there should be more emphasis on practical training regarding medical procedures during their clinical years of study.

According to Figure 1, almost half of participants had not yet rotated in Anaesthesiology and Orthopaedics (45.9\% and 42.6\%, respectively), while the majority of participants had rotated in the remaining six departments. The highest number of medical interns (80.3\%) had rotated in Family Medicine.

Of the procedures listed on the questionnaire, at undergraduate level, every participant had practised the suturing procedure, as this is considered to be the most basic procedure they need to be able to perform (Figure 2). However, less than half (42.6\%) had performed a bone-marrow aspiration.

Table 2 shows the self-perceived readiness to perform basic medical procedures and the frequency at which these preselected medical procedures were performed. For Family Medicine (Table 2), the drainage of a subcutaneous abscess had the highest percentage of participants $(85.7 \%)$ indicating selfperceived readiness to perform the procedure, whereas circumcision had the lowest percentage (49.0\%). Most of the participants $(75.0 \%)$ indicated that they were ready to diagnose and manage a tension pneumothorax, although $89.6 \%$ rarely performed this procedure.

For Internal Medicine, high percentages of participants reported self-perceived readiness to perform a lumbar puncture (100\%), pleural and peritoneal paracentesis (91.3\%), and fine-needle aspiration (93.3\%). However, only the lumbar puncture procedure, and pleural and peritoneal paracentesis were frequently performed. The insertion of a central venous catheter for resuscitation had the lowest indication of readiness (67.3\%).

For procedures done in Obstetrics and Gynaecology, all participants felt ready to perform a Pap smear, which was also the procedure most regularly (90.9\%) performed. Assisted delivery (vacuum extraction) was the procedure least performed ( $97.7 \%$ rarely/never performed) and had the lowest percentage of readiness $(16.3 \%)$.

Results from Orthopaedics showed more than $70 \%$ of participants frequently performed initial management of open fractures, application of plaster of Paris (POP) cylinders and log-rolling of a patient, and over $90 \%$ felt ready to perform these procedures. Reduction of shoulder dislocation was performed regularly by half $(51.4 \%)$ of the participants, but $85.7 \%$ felt that they were ready to perform this procedure. 
Table 1: Socio-demographic characteristics of participating interns $(n=61)$

\begin{tabular}{|lcc}
\hline Characteristic & $\boldsymbol{n}$ & $\%$ \\
\hline Gender & & \\
\hline Male & 28 & 45.9 \\
\hline Female & 33 & 54.1 \\
\hline Year of internship & & \\
\hline First year & 29 & 47.5 \\
\hline Second year & 32 & 52.5 \\
\hline University where MBChB degree obtained & & \\
\hline University of the Free State & 32 & 52.5 \\
\hline University of Cape Town & 2 & 3.3 \\
\hline University of Pretoria & 10 & 16.4 \\
\hline University of KwaZulu-Natal & 1 & 1.6 \\
\hline University of Witwatersrand & 1 & 1.6 \\
\hline Walter Sisulu University & 2 & 3.3 \\
\hline University of Stellenbosch & 13 & 21.3 \\
\hline Method of practical training & 58 & 95.1 \\
\hline Skills lab & 50 & 82.0 \\
\hline First-hand observation & 54 & 88.5 \\
\hline Read about procedure & 58.3 \\
\hline Performed procedure themselves & 5 & \\
\hline
\end{tabular}

Appendectomy in General Surgery was rarely/never performed (73.8\%) and, as a result, half (50.0\%) of the medical interns did not perceive themselves as ready to perform this procedure. Basic surgical knots (both manual and instrumental) were performed by the majority ( $88.4 \%$ ) of medical interns, and $93.0 \%$ were ready to perform this procedure.

Results for Anaesthesiology showed that the majority of medical interns $(>75 \%)$ frequently performed the four pre-selected procedures, and that all of the participants reported performing spinal anaesthesia frequently. Furthermore, the majority of

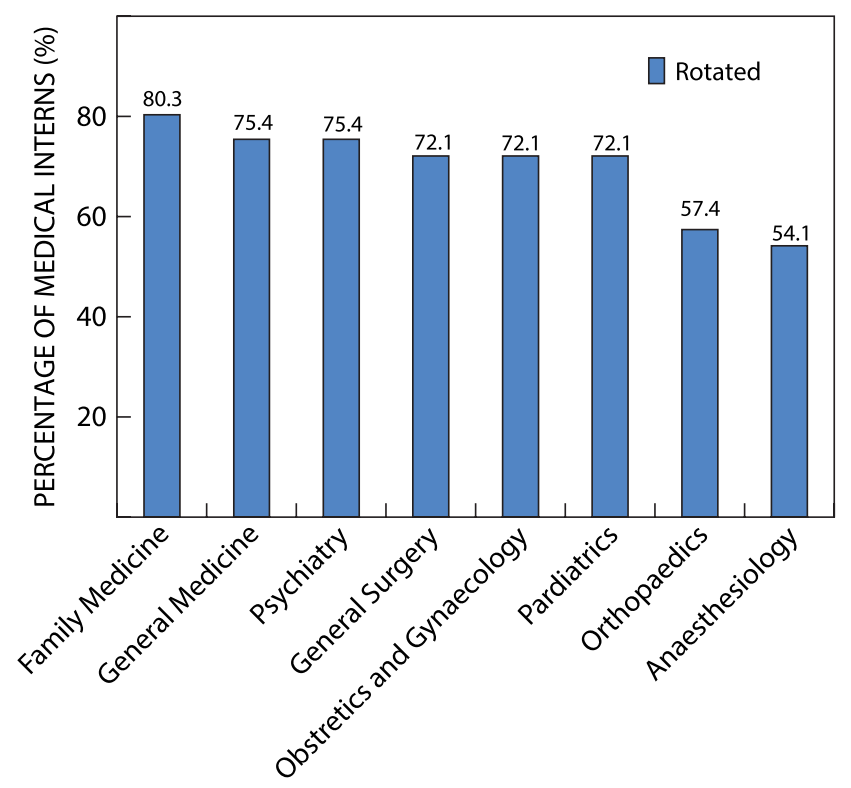

MEDICAL DEPARTMENTS

Figure 1: Percentage of medical interns who completed their rotation in the different departments $(n=61)$.

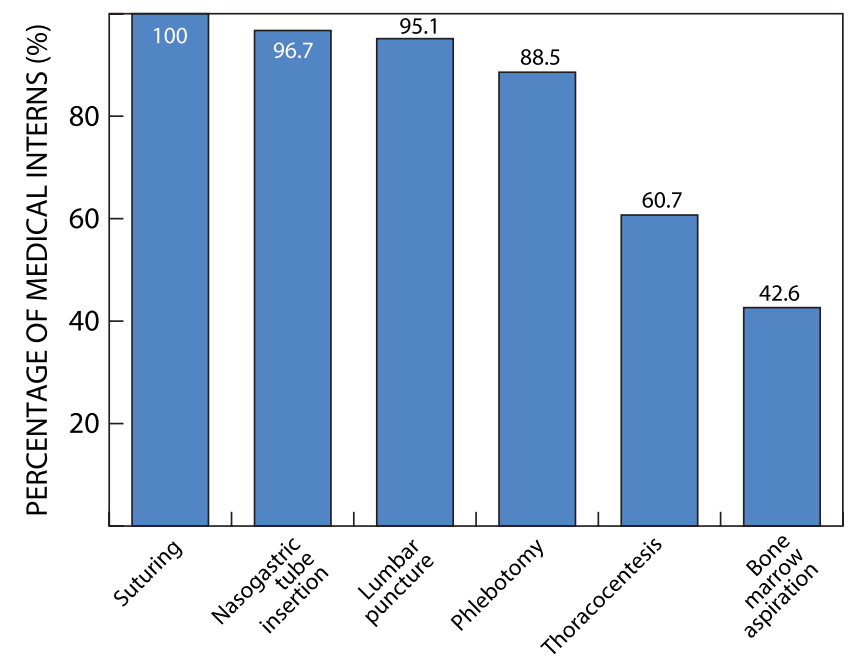

Medical procedures performed at undergraduate level

Figure 2: Percentage of medical interns who have performed listed medical procedures at undergraduate level.

medical interns (>87\%) considered themselves ready to perform these procedures.

During rotation in Psychiatry, the majority of medical interns frequently performed HIV counselling and testing (84.4\%) and management of acute psychosis $(80.0 \%)$, and more than $93 \%$ felt ready to perform these two procedures. Less than half (46.7\%) of the participants had managed a patient with a drug overdose, but about three-quarters (73.3\%) did feel that they were ready to manage such a situation.

Inserting an IV line (95.1\%) and management and treatment of dehydration (92.7\%) in patients in Paediatrics were the most frequently performed procedures, and both procedures also had the highest percentage of participants reporting self-perceived readiness $(95.1 \%$ and $97.6 \%$, respectively).

\section{Discussion}

The procedures practised at undergraduate level indicated that all participating medical interns had performed suturing procedures. The aspiration of bone marrow had the highest percentage of the participants who had not performed this procedure; this may be due to the complicated nature of this procedure, therefore requiring a more senior doctor to perform it.

Interns felt ready to perform the majority of procedures, but more than $50 \%$ reported not being ready to perform circumcisions, episiotomy and perineal repair, assisted delivery and appendectomies. Some procedures in the Departments of Family Medicine, Internal Medicine, Obstetrics and Gynaecology, General Surgery and Psychiatry were rarely performed by at least half of the participants. Most medical interns felt less ready to perform procedures that were done less frequently.

Regarding procedures in Obstetrics and Gynaecology, medical interns were ready to do Pap smears, which they also performed frequently. Pap smears are part of a government surveillance programme for cervical cancer, and medical schools are placing emphasis on the importance of knowing how to perform this crucial procedure. With assisted deliveries rarely performed, few medical interns felt ready to execute this procedure. 
Table 2: Procedures performed and perception of readiness per department (\%)

\begin{tabular}{|c|c|c|c|c|}
\hline \multirow[b]{2}{*}{$\begin{array}{l}\text { Medical department and } \\
\text { pre-selected procedures }\end{array}$} & \multicolumn{2}{|c|}{ Frequency procedure performed } & \multicolumn{2}{|c|}{ Self-perceived readiness to perform procedure } \\
\hline & Performed frequently & Rarely/never performed & Ready to perform & Not ready to perform \\
\hline Insertion of an intercostal drain & 25.0 & 75.0 & 75.0 & 25.0 \\
\hline Circumcision & 34.7 & 65.3 & 49.0 & 51.0 \\
\hline $\begin{array}{l}\text { Diagnosis and management of } \\
\text { tension pneumothorax }\end{array}$ & 10.4 & 89.6 & 75.0 & 25.0 \\
\hline \multicolumn{5}{|l|}{ Internal Medicine $(n=46)$} \\
\hline Lumbar puncture & 95.6 & 4.4 & 100.0 & 0 \\
\hline Pleural and peritoneal paracentesis & 82.6 & 17.4 & 91.3 & 8.7 \\
\hline Fine-needle aspiration & 57.8 & 42.2 & 93.3 & 6.7 \\
\hline \multicolumn{5}{|l|}{ Obstetrics and Gynaecology $(n=44)$} \\
\hline Pap smear & 90.9 & 9.1 & 100.0 & 0 \\
\hline Episiotomy and perineal repair & 16.3 & 83.7 & 46.5 & 53.5 \\
\hline Assisted delivery (vacuum extraction) & 2.3 & 97.7 & 16.3 & 83.7 \\
\hline Manual removal of placenta & 25.6 & 74.7 & 55.8 & 44.2 \\
\hline \multicolumn{5}{|l|}{ Orthopaedics $(n=35)$} \\
\hline Reduction of shoulder dislocation & 51.4 & 48.6 & 85.7 & 14.3 \\
\hline Initial management of open fractures & 71.4 & 28.6 & 94.3 & 5.7 \\
\hline Application of POP cylinders & 74.3 & 25.7 & 94.3 & 5.7 \\
\hline Log-rolling of a patient & 74.3 & 25.7 & 97.1 & 2.9 \\
\hline Appendectomy & 26.2 & 73.8 & 50.0 & 50.0 \\
\hline $\begin{array}{l}\text { Initial assessment of an acutely burnt } \\
\text { patient }\end{array}$ & 37.2 & 62.8 & 76.7 & 23.3 \\
\hline $\begin{array}{l}\text { Basic surgical knots (manual and } \\
\text { instrumental) }\end{array}$ & 88.4 & 11.6 & 93.0 & 7.0 \\
\hline \multicolumn{5}{|l|}{ Anaesthesiology $(n=32)$} \\
\hline Preparation for anaesthesia & 93.8 & 6.2 & 87.5 & 12.5 \\
\hline $\begin{array}{l}\text { Intubation and management of } \\
\text { general anaesthesia }\end{array}$ & 90.6 & 9.4 & 93.8 & 6.3 \\
\hline Spinal anaesthesia & 100.0 & 0 & 96.9 & 3.1 \\
\hline Local anaesthesia & 75.0 & 25.0 & 87.5 & 12.5 \\
\hline \multicolumn{5}{|l|}{ Psychiatry $(n=45)$} \\
\hline Management of a violent patient & 68.9 & 31.1 & 84.4 & 15.6 \\
\hline $\begin{array}{l}\text { Pre-HIV and post-HIV counselling } \\
\text { and testing }\end{array}$ & 84.4 & 15.6 & 95.6 & 4.4 \\
\hline Management of acute psychosis & 80.0 & 20.0 & 93.3 & 6.7 \\
\hline $\begin{array}{l}\text { Management of patient with drug } \\
\text { overdose }\end{array}$ & 46.7 & 53.3 & 73.3 & 26.7 \\
\hline \multicolumn{5}{|l|}{ Paediatrics $(n=40)$} \\
\hline Plan and prescribe PMTCT treatment & 75.0 & 25.0 & 90.2 & 9.8 \\
\hline Paediatric and neonatal resuscitation & 72.5 & 27.5 & 80.5 & 19.5 \\
\hline Insertion of an IV line & 95.1 & 4.9 & 95.1 & 4.9 \\
\hline $\begin{array}{l}\text { Management and treatment of } \\
\text { dehydration }\end{array}$ & 92.7 & 7.3 & 97.6 & 2.4 \\
\hline
\end{tabular}

Notes: HIV = human immunodeficiency virus; IV = intravenous; POP = plaster of Paris; PMTCT = preventing mother-to-child transmission. 
The procedures performed in the Paediatrics Department are of great importance due to the vulnerability of these patients and subsequent high infant mortality rate. All the pre-selected procedures were performed frequently, and medical interns reported a high percentage of self-perceived readiness for all procedures.

Anaesthetic procedures were repeated in other departments, which aided the medical interns' self-perceived readiness to perform these procedures. This perception of sufficient anaesthetic skills should be measured again during the community service year. Previous studies indicated that junior doctors felt less confident about these skills once supervisor assistance was less available or visible during complicated cases.? In the Department of Orthopaedics, most medical interns indicated that they were ready to perform the basic medical procedures, such as log-rolling of a patient and management of open fractures.

In Family Medicine, the majority of medical interns felt that they were ready to diagnose and manage a tension pneumothorax. This is an emergency procedure, which they have to know how to perform, although the procedure is not commonly done. The procedure with the highest percentage that medical interns reported not being ready to perform was circumcision.

In view of the HIV epidemic in South Africa, emphasis is placed on adequate knowledge of the treatment and management of affected patients seen in the Department of Psychiatry. Almost all the medical interns perceived themselves as ready to perform pre- and post-HIV counselling and testing, a procedure they frequently performed.

Confidence to perform basic medical procedures is essential for actual procedural competence. ${ }^{5}$ Both academic lecturers and clinical supervisors have important roles to play in not only teaching these skills, but also aiding students and interns to become confident in the very same skills.

Although adequate practical training on common procedures should be provided during undergraduate training, this study suggests provision of sufficient senior doctors/family physicians at district hospitals and community health centres, to continue providing supervision and training of interns, community service doctors and junior doctors. This will provide continuous opportunity to improve on junior doctors' confidence to perform procedural skills. Most of the procedures the interns are struggling with in different domains are encountered at primary health care level; therefore, it would be ideal if all interns spent adequate time at district hospitals.

\section{Study limitations}

The study sample was small. Future studies should include more institutions to get a broader view of South African interns. This study also relied on self-reporting, the effect of which we attempted to overcome by the anonymous nature of the questionnaire.

\section{Conclusions}

The study showed that, in most cases, medical interns considered themselves ready to perform the procedures that they more frequently practised. Similarly, most medical interns felt less ready to perform procedures that were rarely practised. There were, however, procedures that were frequently performed that the interns considered themselves not ready to perform, such as circumcisions and insertion of a central venous catheter for resuscitation. The opposite was also true: some procedures rarely performed had a high percentage of medical interns reporting themselves ready to perform. These included insertion of an intercostal drain, diagnosis and management of tension pneumothorax, pleural and peritoneal paracentesis, manual removal of placenta, initial assessment of an acutely burnt patient, and management of a patient with drug overdose.

Most medical interns indicated that they favour a more practical training-focused curriculum during their clinical years, as they feel that this would improve their readiness to perform basic medical procedures. This shows that there is room for improvement in the $\mathrm{MBChB}$ curriculum to increase the focus to a more specific practical approach during the clinical years of study.

\section{Recommendations}

In 2013, the University of the Free State developed and implemented a clinical simulation unit, using high-end technology to simulate clinical experiences, especially those events and procedures that were previously difficult to train due to limited skilled clinical teachers/supervisors and ethical/safety issues. ${ }^{10}$ Furthermore, the technology and supervision in such a unit prevents the knowledge transfer experienced during peerto-peer and/or self-directed learning going awry. The success of this development was not tested in this project, but a future project can compare and determine whether the perceived competence improved.

We recommend that more time be allocated to the practising of procedures during clinical years, and that medical students should be exposed to the hospital environment at an earlier stage in their studies. Exposure to the hospital environment could, for example, be in the form of frequent clinic visits in the first and second year of study.

Medical interns should also be exposed to different environments, such as facilities with scarce resources and challenging working conditions. This will equip medical interns with the ability to perform the procedures with confidence and competence.

Acknowledgements - Ms Theanette Mulder, medical editor, School of Medicine, University of the Free State, for technical and editorial preparation of the manuscript.

Conflict of interest - The authors declare that they have no financial or personal relationship(s) which may have inappropriately influenced them in writing this paper.

\section{References}

1. Medical and Dental Professions Board, Health Professions Council of South Africa. HPCSA Internship guidelines 2012. Pretoria: HPCSA, 2012.

2. Bola S, Trollip E, Parkinson F. The state of South African internships: a national survey against HPCSA guidelines. S Afr Med J. 2015;105(7):535-9. doi: 10.7196/SAMJnew.7923.

3. Prinsloo EAM. A two-year internship programme for South Africa. SA Fam Pract. 2005;47(5):3. doi:10.1080/20786204.2005.10873222.

4. Meintjes Y. The 2-year internship training. S Afr Med J. 2003;93(5):336-7. 
5. Draper CE, Louw GJ. Competence for internship: perceptions of finalyear medical students. Edu Health (Abingdon). 2012;25(1):16-23. doi:10.4103/1357-6283.99202.

6. Mclnerney NM, Larkin JO, O'Callaghan AP, et al. Changes in medical student's perspective on priorities in undergraduate education and training following completion of internship. Int J Innov Res Educ Sci. 2014;2(2):54-9.

7. Nkabinde TC, Ross A, Reid S, et al. Internship training adequately prepares South African medical graduates for community service - with exceptions. S Afr Med J. 2013;103(12):930-4. doi:10.7196/samj.6702.

8. Jaschinski J, De Villiers MR. Factors influencing the development of practical skills of interns working in regional hospitals of the Western
Cape province of South Africa. SA Fam Pract. 2008;50(1):70. doi:10.10 80/20786204.2008.10873676.

9. Frambach JM, Manuel BA, Fumo AM, et al. Students' and junior doctors' preparedness for the reality of practice in sub-Saharan Africa. Med Teach. 2015;37(1):64-73. doi:10.3109/0142159X.2014.920490.

10. Labuschagne MJ, Nel MM, Nel PP, et al. Recommendations for the establishments of a clinical simulation unit to train South African medical students. Afr J Health Prof Educ. 2014;6(2):138-42. doi:10.7196/ajhpe.345. 